\title{
Avelumab, an anti-PD-L1 antibody, in patients with locally advanced or metastatic breast cancer: a phase 1b JAVELIN Solid Tumor study
}

\author{
Luc Y. Dirix $1{ }^{1}$ - Istvan Takacs ${ }^{2} \cdot$ Guy Jerusalem $^{3} \cdot$ Petros Nikolinakos $^{4} \cdot$ Hendrik-Tobias Arkenau ${ }^{5,6}$. \\ Andres Forero-Torres $^{7} \cdot$ Ralph Boccia $^{8} \cdot$ Marc E. Lippman $^{9} \cdot$ Robert Somer $^{10} \cdot$ Martin Smakal $^{11}$. \\ Leisha A. Emens ${ }^{12}$ • Borys Hrinczenko ${ }^{13}$ - William Edenfield ${ }^{14} \cdot$ Jayne Gurtler $^{15}$ • Anja von Heydebreck ${ }^{16}$. \\ Hans Juergen Grote ${ }^{16} \cdot$ Kevin Chin $^{17} \cdot$ Erika P. Hamilton $^{18}$
}

Received: 29 September 2017 / Accepted: 6 October 2017 / Published online: 23 October 2017

(c) The Author(s) 2017. This article is an open access publication

\begin{abstract}
Purpose Agents targeting programmed death receptor 1 (PD-1) or its ligand (PD-L1) have shown antitumor activity in the treatment of metastatic breast cancer (MBC). The aim of this study was to assess the activity of avelumab, a PD-L1 inhibitor, in patients with MBC.

Methods In a phase 1 trial (JAVELIN Solid Tumor; NCT01772004), patients with MBC refractory to or progressing after standard-of-care therapy received avelumab intravenously $10 \mathrm{mg} / \mathrm{kg}$ every 2 weeks. Tumors were assessed every 6 weeks by RECIST v1.1. Adverse events (AEs) were graded by NCI-CTCAE v4.0. Membrane PD-L1
\end{abstract}

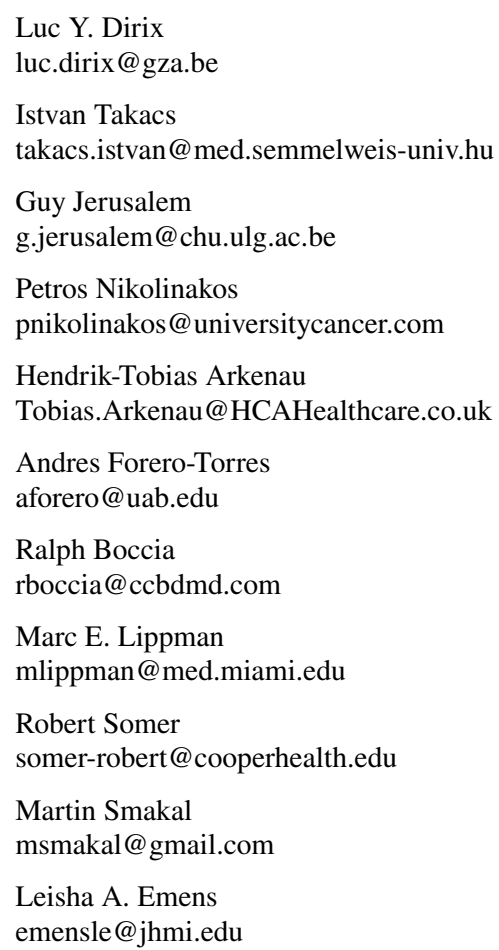

expression was assessed by immunohistochemistry (Dako PD-L1 IHC 73-10 pharmDx).

Results A total of 168 patients with MBC, including 58 patients with triple-negative breast cancer (TNBC), were treated with avelumab for 2-50 weeks and followed for $6-15$ months. Patients were heavily pretreated with a median of three prior therapies for metastatic or locally advanced disease. Grade $\geq 3$ treatment-related AEs occurred in 13.7\% of patients, including two treatment-related deaths. The confirmed objective response rate (ORR) was 3.0\% overall (one complete response and four partial responses) and 5.2\% in patients with TNBC. A trend toward a higher ORR was seen

\author{
Borys Hrinczenko \\ borys.hrinczenko@hc.msu.edu \\ William Edenfield \\ jedenfield@ghs.org \\ Jayne Gurtler \\ drgurtler@metairieoncologists.org \\ Anja von Heydebreck \\ Anja.von.Heydebreck@merckgroup.com \\ Hans Juergen Grote \\ hans-juergen.grote@merck.de \\ Kevin Chin \\ kevin.chin@emdserono.com \\ Erika P. Hamilton \\ ehamilton@tnonc.com \\ Sint Augustinus-University of Antwerp, Antwerp, Belgium \\ 2 Semmelweis University, Budapest, Hungary \\ 3 CHU Sart Tilman Liege and Liege University, Liege, \\ Belgium \\ 4 University Cancer \& Blood Center, LLC, Athens, GA, USA \\ 5 Sarah Cannon Research Institute, London, UK
}


in patients with PD-L1+ versus PD-L1- tumor-associated immune cells in the overall population $(16.7 \%$ vs. $1.6 \%)$ and in the TNBC subgroup ( $22.2 \%$ vs. $2.6 \%$ ).

Conclusion Avelumab showed an acceptable safety profile and clinical activity in a subset of patients with MBC. PD-L1 expression in tumor-associated immune cells may be associated with a higher probability of clinical response to avelumab in MBC.

Keywords Avelumab - Metastatic breast cancer $\cdot$ Triplenegative breast cancer $\cdot$ PD-L1 $\cdot$ Second-line

\section{Introduction}

Despite advances in the treatment of breast cancer and an encouraging 5-year overall survival rate of approximately $90 \%$ in the United States, up to $30 \%$ of patients with an early-stage diagnosis eventually progress to incurable metastatic disease, and $6 \%$ of patients have metastatic disease at diagnosis $[1,2]$. Treatment of metastatic breast cancer (MBC) is based on molecular subtype and may include chemotherapy, human epidermal growth factor receptor 2 (HER2)-directed agents, and endocrine-based therapies or agents targeted to mechanistic target of rapamycin or CDK4/6 for those tumors overexpressing estrogen receptor (ER) and/or progesterone receptor (PR) [3]. Approximately, 15-20\% of patients have breast cancers lacking expression of ER, PR, or HER2, which are termed triple-negative breast cancer (TNBC). For these patients, standard treatment is cytotoxic chemotherapy, which is limited by poor tolerability and short duration of response [4-6]. Thus, new therapies are needed for patients with

\footnotetext{
6 University College London Cancer Institute, London, UK

7 University of Alabama, Birmingham, AL, USA

8 Center for Cancer and Blood Disorders, Bethesda, MD, USA

9 University of Miami Miller School of Medicine, Miami, FL, USA

10 Cooper Hospital University Medical Center, Camden, NJ, USA

11 Nemocnice Horovice, Onkologicke Oddelení, Horovice, Czech Republic

12 The John Hopkins University School of Medicine, Baltimore, MD, USA

13 Michigan State University, East Lansing, MI, USA

14 Greenville Hospital System, Greenville, SC, USA

15 Metairie Oncologist LLC, Metairie, LA, USA

16 Merck KGaA, Darmstadt, Germany

17 EMD Serono, Billerica, MA, USA

18 Sarah Cannon Research Institute, Nashville, TN, USA
}

MBC whose disease has progressed following standard therapies.

Immune checkpoint inhibitors, particularly agents targeting programmed death receptor 1 (PD-1) or its ligand (PD-L1), are being increasingly explored as a potential treatment strategy in various cancers [7]. Breast cancers express PD-L1, with higher expression often seen in TNBC tumors [8-10]. Binding of PD-L1 to its receptor on T cells, PD-1, inhibits adaptive immune responses in the tumor microenvironment, which enables tumor cell escape from immune cells [11-13]. The presence of tumor-infiltrating lymphocytes (TILs) in breast cancer has been shown to have a strong prognostic association [14]. High TIL levels are associated with tumors having PD-L1 expression, and PD-L1+ tumors with high TILs have better outcomes $[9,10,15]$. PD-L1 expression may serve as a marker of immune activity, and local immunosuppression of TILs via the PD-L1/PD-1 pathway may be an important means of tumor immune evasion [8, 14]. Inhibition of the PD-L1/PD-1 axis with monoclonal antibodies may be one means of restoring immune surveillance and cell-mediated antitumor activity, and studies of anti-PD-L1/PD-1 agents have shown durable antitumor responses in patients with various advanced cancers [7, 16]. Early-phase studies have suggested that these agents may also have clinical activity in breast cancer, particularly in the TNBC subtype [17-19].

Avelumab (MSB0010718C) is a human anti-PD-L1 IgG1 monoclonal antibody that inhibits the interaction between PD-1 and PD-L1, leaving PD-1/PD-L2 interactions intact [20]. Unlike other anti-PD-L1/PD-1 antibodies approved or in advanced clinical development, avelumab has been shown to induce antibody-dependent cell-mediated cytotoxicity (ADCC) of tumor cells in preclinical studies, suggesting it may potentially have an additional mechanism of action [21-23]. In phases 1 and 2 clinical studies, avelumab has been well tolerated and associated with durable responses in patients with various advanced tumors, including Merkel cell carcinoma (MCC), nonsmall cell lung cancer, and urothelial carcinoma [20, 24-26]. Avelumab is approved by the US Food and Drug Administration for the treatment of metastatic MCC and locally advanced or metastatic urothelial carcinoma that has progressed during or after platinum-containing chemotherapy [27]. In the phase 1a part of the JAVELIN Solid Tumor study, avelumab was safely administered by intravenous infusion every 2 weeks and had a predictable pharmacokinetic profile at doses of up to $20 \mathrm{mg} / \mathrm{kg}$; the $10 \mathrm{mg} / \mathrm{kg}$ dose was selected for further study in phase $1 \mathrm{~b}$ dose-expansion cohorts enrolling a range of tumor types [20]. Here, we report the evaluation of avelumab in a phase $1 \mathrm{~b}$ cohort of patients with MBC as part of the JAVELIN Solid Tumor trial. 


\section{Methods}

\section{Study design and patients}

JAVELIN Solid Tumor is an international, open-label, phase 1 trial in patients with advanced solid malignancies. In the dose-expansion cohort reported here, eligible patients had histologically confirmed locally advanced or MBC that was refractory to or had progressed after standard-of-care therapy. Eligible patients were aged $\geq 18$ years and had an Eastern Cooperative Oncology Group (ECOG) performance status of 0 or 1 , an estimated life expectancy of $>3$ months, and adequate hepatic, renal, and hematologic function. Patients had received $\leq 3$ prior lines of cytotoxic therapy (excluding systemic therapy that was not considered cytotoxic) and, unless contraindicated, were required to have received prior treatment with a taxane and anthracycline in any therapeutic setting. Patients had $\geq 1$ measurable lesion per Response Evaluation Criteria In Solid Tumors (RECIST) version 1.1 [28]. A biopsy or surgical specimen for biomarker testing collected within 90 days prior to the first avelumab administration was required. Patients were unselected for PD-L1 expression and breast cancer subtype. Patients were enrolled in accordance with an approved protocol, international standards of good clinical practice, and institutional safety monitoring, and written informed consent was provided by patients.

\section{Procedures and assessments}

Patients received avelumab (EMD Serono, Research \& Development Institute, Billerica, MD, USA, a business of Merck KGaA, Darmstadt, Germany) $10 \mathrm{mg} / \mathrm{kg}$ intravenously every 2 weeks until confirmed disease progression, unacceptable toxicity, or other protocol-based criteria for withdrawal occurred. Safety and tolerability were assessed per the National Cancer Institute's Common Terminology Criteria for Adverse Events (NCI-CTCAE), version 4.0. Potential immune-related adverse events (AEs) were identified using a prespecified list of Medical Dictionary for Regulatory Activities terms. Signs and symptoms of an infusion-related reaction, such as fever, chills, or rigors reported on the same day or the day following treatment, were queried with investigators to ascertain whether an $\mathrm{AE}$ of infusion-related reaction should be recorded. Premedication with diphenhydramine and acetaminophen was required 30-60 min before all infusions of avelumab to mitigate the occurrence of infusionrelated reactions. Tumors were evaluated radiographically at baseline and every 6 weeks for the first 12 months, then every 12 weeks thereafter. Best overall response, duration of response, and progression-free survival were determined according to RECIST version 1.1 per investigator.
HER2, ER, and PR statuses were obtained from patient records. Levels of PD-L1 protein expressed on tumor cell membranes and on membranes and/or cytoplasm of immune cells within the tumor microenvironment were assessed by immunohistochemistry (IHC) staining of formalin-fixed, paraffin-embedded tissue sections of the most recent suitable biopsy or surgical specimen using a proprietary assay (PD-L1 IHC 73-10 pharmDx; Dako, Carpinteria, CA, USA) with an anti-PD-L1 rabbit monoclonal antibody. PD-L1 expression was assessed prospectively by central independent reviewers, who were blinded to any clinical data; expression was based on the percentages of tumor cells expressing PD-L1: 1 and 5\% thresholds with any staining intensity and a $25 \%$ threshold with moderate to high staining. Additionally, dense aggregates of tumor-associated immune cells (identified as nonmalignant cells based on morphology) adjacent to tumor cells were assayed using a defined threshold of $10 \%$ of immune cells expressing PD-L1 at any staining intensity.

\section{Statistical methods}

Enrollment of approximately 150 patients was planned for this cohort, and safety and activity were analyzed in all patients who received $\geq 1$ dose of avelumab. The prespecified primary analysis occurred 6 months after the date of the first dose in the last patient enrolled. The objective response rate (ORR), defined as the proportion of patients with a confirmed best response of complete or partial response, was calculated with corresponding Clopper-Pearson CIs. Time-to-event endpoints (duration of response, progressionfree survival, and overall survival) were estimated using Kaplan-Meier method, and CIs for the median were determined using the Brookmeyer-Crowley method. The trial is registered with ClinicalTrials.gov as NCT01772004.

\section{Results}

\section{Patients}

Of 266 patients screened, 168 patients with histologically confirmed MBC refractory to or progressing after standardof-care therapy were enrolled and treated with avelumab between November 2013 and February 2015 (Table 1, Appendix Tables 4, 5). Of these 168 patients, 26 patients (15.5\%) had HER2-positive disease (irrespective of ER and PR status), 72 patients (42.9\%) had hormone-receptor-positive/HER2-negative disease, and 58 patients $(34.5 \%)$ had TNBC. Median age was 55 (range 31-81) years. Patients had received a median of three prior therapies for metastatic disease, and 123 patients $(73.2 \%)$ had received $\geq 2$ prior anticancer regimens for metastatic or locally advanced disease (Table 1; Appendix Tables 4, 6). Median time since 
Table 1 Selected baseline characteristics

\begin{tabular}{|c|c|c|c|c|}
\hline \multirow{2}{*}{$\frac{\text { Characteristics }}{\text { Median age, years (range) }}$} & & \multicolumn{2}{|l|}{ Total population $N=168$} & TNBC subgroup $(n=58)$ \\
\hline & & $55(31-81)$ & & $52.5(31-80)$ \\
\hline \multicolumn{5}{|l|}{ Age category, $n(\%)$ (years) } \\
\hline \multicolumn{2}{|l|}{$<65$} & \multicolumn{2}{|l|}{$140(83.3)$} & $54(93.1)$ \\
\hline$\geq 65$ & & \multicolumn{2}{|l|}{$28(16.7)$} & $4(6.9)$ \\
\hline \multicolumn{5}{|l|}{ Sex, $n(\%)$} \\
\hline \multicolumn{2}{|l|}{ Male } & \multicolumn{2}{|l|}{$1(0.6)$} & 0 \\
\hline Female & & \multicolumn{2}{|l|}{$167(99.4)$} & $58(100)$ \\
\hline \multicolumn{5}{|l|}{ Race or ethnic group, $n(\%)$} \\
\hline \multicolumn{2}{|l|}{ White } & \multicolumn{2}{|l|}{$143(85.1)$} & $45(7.8)$ \\
\hline \multicolumn{2}{|l|}{ Black or African American } & \multicolumn{2}{|l|}{$16(9.5)$} & $9(15.5)$ \\
\hline \multicolumn{2}{|l|}{ Asian } & \multicolumn{2}{|l|}{$3(1.8)$} & $1(1.7)$ \\
\hline Other & & $6(3.6)$ & & $3(5.2)$ \\
\hline Geographic region, $n(\%)$ & & & & \\
\hline United States & & $112(66.7)$ & & $48(82.8)$ \\
\hline Europe & & $56(33.3)$ & & $10(17.2)$ \\
\hline ECOG PS, $n(\%)$ & & & & \\
\hline 0 & & $83(49.4)$ & & $33(56.9)$ \\
\hline 1 & & $85(50.6)$ & & $25(43.1)$ \\
\hline Smoking history, $n(\%)$ & & & & \\
\hline Never smoker & & 107 (63.7) & & $36(62.1)$ \\
\hline Current or former smoker & & $50(29.8)$ & & $17(29.3)$ \\
\hline Unknown & & $11(6.5)$ & & $5(8.6)$ \\
\hline Histological subtype of tumor, $n(\%)$ & & & & \\
\hline Ductal & & $94(56.0)$ & & $36(62.1)$ \\
\hline Lobular & & $6(3.6)$ & & 0 \\
\hline Carcinoma, not otherwise specified & & $14(8.3)$ & & $6(10.3)$ \\
\hline Other $^{\mathrm{a}}$ & & $54(32.1)$ & & $16(27.6)$ \\
\hline Molecular subtype, $n(\%)$ & & & & \\
\hline TNBC & & $58(34.5)$ & & $58(100)$ \\
\hline HER2-/ER+ or PR+ & & $72(42.9)$ & & - \\
\hline HER2+ & & $26(15.5)$ & & - \\
\hline Unknown $^{\mathrm{b}}$ & & $12(7.1)$ & & - \\
\hline Median time since first diagnosis, mon & & $53.5(7.3-407.5)$ & & $40.3(7.3-241.0)$ \\
\hline Median time since diagnosis of metasta & months $(\text { range })^{\mathrm{c}}$ & $21.6(0.7-176.8)$ & & $13.2(0.7-176.8)$ \\
\hline $\begin{array}{l}\text { Prior anticancer lines of therapy for me } \\
(\%)^{\mathrm{d}}\end{array}$ & locally advanced d & & & \\
\hline$\leq 1$ & & $45(26.8)$ & & $29(50.0)$ \\
\hline 2 & & $35(20.8)$ & & $16(27.6)$ \\
\hline$\geq 3$ & & $88(52.4)$ & & $13(22.4)$ \\
\hline Median (range) & & $3(0-10)$ & & $2(1-6)$ \\
\hline PD-L1 expression status, $n / N(\%)^{\mathrm{e}}$ & PD-L1+ & PD-L1- & PD-L1+ & PD-L1- \\
\hline$\geq 1 \%$ tumor cells & $85 / 136(62.5)$ & $51 / 136(37.5)$ & $33 / 48(68.8)$ & $15 / 48(31.2)$ \\
\hline$\geq 5 \%$ tumor cells & 23/136 (16.9) & $113 / 136(83.1)$ & $13 / 48(27.1)$ & $35 / 48(72.9)$ \\
\hline$\geq 25 \%$ tumor cells & $3 / 136(2.2)$ & $133 / 136(97.8)$ & $2 / 48(4.2)$ & $46 / 48(95.8)$ \\
\hline$\geq 10 \%$ tumor-associated immune cells & $12 / 136(8.8)$ & $124 / 136(91.2)$ & $9 / 48(18.8)$ & $39 / 48(81.2)$ \\
\hline
\end{tabular}

ECOG PS Eastern Cooperative Oncology Group performance status, ER estrogen receptor, HER2 human epidermal growth factor receptor 2, $P D-L 1$ programmed death-ligand $1, P R$ progesterone receptor, $T N B C$ triple-negative breast cancer

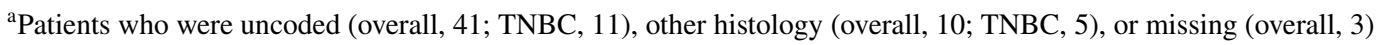

${ }^{b}$ Unknown molecular subtype was due to incomplete information in the medical records database (ER/PR status known, but HER2 status 
Table 1 (continued)

unknown in four patients) or to information collected retrospectively (molecular subtype status was from post-baseline samples in eight patients and therefore was not used for baseline characterization)

${ }^{\mathrm{c}}$ Time since diagnosis of metastatic disease was missing for eight patients in the overall study population and six patients in the TNBC subgroup

${ }^{\mathrm{d}}$ Regimen for metastatic disease may have included hormonal therapy, either alone or in combination with chemotherapy. Systemic therapies that were not necessarily cytotoxic are included in the number of prior regimens reported here, but the number of prior cytotoxic therapies permitted was $\leq 3$

${ }^{\mathrm{e}}$ Non-evaluable specimens included those that were missing, of poor quality or quantity (insufficient tissue on slide or insufficient tumor sample), or otherwise not available to provide results; all biopsy or surgical specimens were required to be collected within 90 days of first administration of avelumab

diagnosis of metastatic disease was 22 months (range 3 weeks to $>14.7$ years). Of 58 patients with TNBC, $50 \%$ had received $\geq 2$ prior lines of therapy for metastatic disease and median time since diagnosis was 13 months. Tumor specimens were evaluable for PD-L1 expression in 136 patients $(81.0 \%)$, and based on a threshold of $\geq 1 \%$ tumor cell staining, 85 of $136(62.5 \%)$ had PD-L1+ tumors. Using $\mathrm{a} \geq 10 \%$ threshold for PD-L1 expression in tumor-associated immune cells, 12 of 136 evaluable patients $(8.8 \%)$ had PD-L1+ tumors.

At the time of data cutoff (February 27, 2015), patients had received a median of four avelumab (range 1-23) doses and had a median treatment duration of 8.0 (range 2-50) weeks. Median duration of follow-up was 10.0 (range 6.0-15.2) months, and nine patients (5.4\%) remained on avelumab treatment at data cutoff. Disease progression was the most common reason for treatment discontinuation (74.4\%).

\section{Safety}

Treatment-related AEs of any grade occurred in 115 patients (68.5\%), including a grade $\geq 3$ event in 23 patients (13.7\%; Table 2; Appendix Table 7). The most commonly occurring treatment-related AEs of any grade ( $>10 \%$ of patients) were fatigue (19.0\%), infusion-related reaction (14.3\%), and nausea (13.1\%). Treatment-related AEs of any grade classified as immune-related occurred in 17 patients (10.1\%): hypothyroidism (4.8\%), autoimmune hepatitis and pneumonitis (1.8\% each), thrombocytopenia (1.2\%), and antinuclear antibody production, dry eye, elevated rheumatoid factor, hyperthyroidism, and pemphigoid skin reaction $(0.6 \%$ each; Appendix Table 8 ). Four patients $(2.4 \%)$ had a grade $\geq 3$ immune-related, treatment-related AE (Appendix Table 8), including three patients (1.8\%) with grade 3 autoimmune hepatitis and one patient each with grade 3 pneumonitis and grade 4 thrombocytopenia ( $0.6 \%$ each). One patient with autoimmune hepatitis who had progressive liver metastasis died of acute liver failure.

Of eight patients (4.8\%) who discontinued avelumab because of a treatment-related $\mathrm{AE}$, three (1.8\%) discontinued because of an immune-related AE (autoimmune hepatitis $[n=2$, both grade 3$]$ and pemphigoid $[n=1$, grade
2]); other treatment-related AEs resulting in discontinuation were elevated $\gamma$-glutamyl transferase $(n=2$, grades 3 and 4$)$, elevated aspartate aminotransferase $(n=1$, grade 3 ), elevated creatine phosphokinase $(n=1$, grade 1$)$, and respiratory distress $(n=1$, grade 5$)$. Two patients $(1.2 \%)$ had a treatment-related death, including the patient with acute liver failure described above and a patient with metastatic lesions of liver, lung, and soft tissues and a history of respiratory disorders (cough, dyspnea, and pneumonia) who died of respiratory distress. The patient with treatment-related respiratory distress also presented with unspecified sepsis, most likely secondary to healthcare-associated pneumonia, and extensive pulmonary metastasis.

\section{Antitumor activity}

Based on investigator assessment, five patients had a confirmed objective response, including one complete response and four partial responses, resulting in a confirmed ORR of $3.0 \%$ (95\% CI 1.0-6.8; Table 3). Notably, three of five confirmed responders $(60.0 \%)$ had TNBC, resulting in an ORR of 5.2\% in this subset (Appendix Table 9). The other two confirmed responders had HER2- ER/PR+ disease, and the ORR in this subset was 2.8\% (Appendix Table 9). Four out of five responses were ongoing at data cutoff, and median duration of response was not reached (95\% CI 28.7, ne). The unconfirmed ORR in the total population was $4.8 \%$, including one complete response and seven partial responses, and the median time to response was 11.4 weeks (range 5.7-17.6 weeks) (Fig. 1). Stable disease was the best response in 42 patients (25.0\%), and the disease control rate (DCR) - based on patients with a confirmed response or stable disease-was $28.0 \%$ (47 of 168) (Table 3). Within the TNBC subgroup, 15 patients $(25.9 \%)$ had stable disease as best response, and the DCR was 31.0\% (18 of 58). Of the 47 patients with a best response of complete response, partial response, or stable disease, 14 (29.8\%) remained progression free for $\geq 24$ weeks.

Of 140 patients who had evaluable data for sum of target lesion diameter at baseline and on study, 39 patients (27.9\%) experienced tumor shrinkage of any level. Sixteen (11.4\%) of these patients had tumor shrinkage of $\geq 30 \%$, 
Table 2 Treatment-related adverse events occurring at any grade in $\geq 5 \%$ of patients or grade $\geq 3$ in any patient

\begin{tabular}{|c|c|c|c|c|c|}
\hline$N=168$ & Any grade & Grades $1-2$ & Grade 3 & Grade 4 & Grade 5 \\
\hline Any event, $n(\%)$ & $115(68.5)$ & $92(54.8)$ & $16(9.5)$ & $5(3.0)$ & $2(1.2)$ \\
\hline Fatigue & $32.9(19.0)$ & $29(17.3)$ & $3(1.8)$ & 0 & 0 \\
\hline Infusion-related reaction & $24(14.3)$ & $24(14.3)$ & 0 & 0 & 0 \\
\hline Nausea & $22(13.1)$ & $22(13.1)$ & 0 & 0 & 0 \\
\hline Diarrhea & $15(8.9)$ & $15(8.9)$ & 0 & 0 & 0 \\
\hline Arthralgia & $13(7.7)$ & $12(7.1)$ & $1(0.6)$ & 0 & 0 \\
\hline Decreased appetite & $12(7.1)$ & $12(7.1)$ & 0 & 0 & 0 \\
\hline Influenza-like illness & $11(6.5)$ & $11(6.5)$ & 0 & 0 & 0 \\
\hline Dyspnea exertional & $5(3.0)$ & $4(2.4)$ & $1(0.6)$ & 0 & 0 \\
\hline Elevated AST & $4(2.4)$ & $3(1.8)$ & $1(0.6)$ & 0 & 0 \\
\hline Elevated GGT & $4(2.4)$ & $1(0.6)$ & $1(0.6)$ & $2(1.2)$ & 0 \\
\hline Anemia & $3(1.8)$ & 0 & $2(1.2)$ & $1(0.6)$ & 0 \\
\hline Autoimmune hepatitis & $3(1.8)$ & 0 & $3(1.8)$ & 0 & 0 \\
\hline Elevated ALT & $3(1.8)$ & $2(1.2)$ & $1(0.6)$ & 0 & 0 \\
\hline Hypoxia & $3(1.8)$ & $2(1.2)$ & $1(0.6)$ & 0 & 0 \\
\hline Pneumonitis & $3(1.8)$ & $2(1.2)$ & $1(0.6)$ & 0 & 0 \\
\hline Axillary pain & $2(1.2)$ & $1(0.6)$ & $1(0.6)$ & 0 & 0 \\
\hline Thrombocytopenia & $2(1.2)$ & $1(0.6)$ & 0 & $1(0.6)$ & 0 \\
\hline Acute hepatic failure & $1(0.6)$ & 0 & 0 & 0 & $1(0.6)$ \\
\hline Cardiac arrest & $1(0.6)$ & 0 & 0 & $1(0.6)$ & 0 \\
\hline Hypertriglyceridemia & $1(0.6)$ & 0 & $1(0.6)$ & 0 & 0 \\
\hline Hypokalemia & $1(0.6)$ & 0 & 0 & $1(0.6)$ & 0 \\
\hline Neutropenia & $1(0.6)$ & 0 & 0 & $1(0.6)$ & 0 \\
\hline Neutrophil count decreased & $1(0.6)$ & 0 & $1(0.6)$ & 0 & 0 \\
\hline Noncardiac chest pain & $1(0.6)$ & 0 & $1(0.6)$ & 0 & 0 \\
\hline Pleuritic pain & $1(0.6)$ & 0 & $1(0.6)$ & 0 & 0 \\
\hline Proteinuria & $1(0.6)$ & 0 & $1(0.6)$ & 0 & 0 \\
\hline Pulmonary arterial hypertension & $1(0.6)$ & 0 & $1(0.6)$ & 0 & 0 \\
\hline Respiratory distress & $1(0.6)$ & 0 & 0 & 0 & $1(0.6)$ \\
\hline Respiratory failure & $1(0.6)$ & 0 & 0 & $1(0.6)$ & 0 \\
\hline
\end{tabular}

$A L T$ alanine aminotransferase, $A S T$ aspartate aminotransferase, $G G T \gamma$-glutamyl transferase including two patients with progressive disease by RECIST who had a partial response by modified immunerelated response criteria (Fig. 2). Among 46 evaluable patients with TNBC, 21 (45.7\%) had tumor shrinkage of any level, which was by $\geq 30 \%$ in ten patients $(21.7 \%)$ (Fig. 3).

No trends for response were observed based on patient or disease characteristics, including age, race, ECOG status, and prior lines of therapy (Appendix Table 9). In addition, no efficacy trends were seen in subgroups defined by PD-L1 expression in tumor cells at different thresholds (Appendix Table 10). However, in evaluable patients with PD-L1+ or PD-L1 - tumor-associated immune cells (10\% staining cutoff), the ORR was $16.7 \%$ ( 2 of 12 patients) versus $1.6 \%$ ( 2 of 124 patients) in the overall group, and $22.2 \%$ ( 2 of 9 patients) versus $2.6 \%$ ( 1 of 39 patients) in patients with TNBC.

\section{Discussion}

In this study of 168 heavily pretreated patients with MBC refractory to or progressing after standard-of-care therapy, avelumab monotherapy showed an acceptable safety profile with an incidence of grade $\geq 3$ treatment-related AEs (13.7\%) comparable with other anti-PD-L1/PD-1 therapies in MBC $[17,18]$. Antitumor activity was modest, with a confirmed ORR of 3.0\% based on one complete response and four partial responses. Of these five responders, three were in the TNBC subgroup (ORR 5.2\%). Importantly, responses were durable, and the median duration of response was not reached during available follow-up. Tumor shrinkage occurred in $27.9 \%$ of evaluable patients in the overall MBC group and in $45.7 \%$ of patients with TNBC. The DCR was $28.0 \%$ in the total patient group and $31.0 \%$ in patients with TNBC. Preclinical studies suggest that avelumab may mediate tumor lysis through 
Table 3 Antitumor activity of avelumab

\begin{tabular}{|c|c|c|}
\hline & Study population $N=168$ & TNBC subgroup $n=58$ \\
\hline Complete response, $n(\%)$ & $1(0.6)$ & 0 \\
\hline Partial response, $n(\%)$ & $4(2.4)$ & $3(5.2)$ \\
\hline Stable disease, ${ }^{\mathrm{a}} n(\%)$ & $42(25.0)$ & $15(25.9)$ \\
\hline Progressive disease, $n(\%)$ & $106(63.1)$ & $38(65.5)$ \\
\hline Nonevaluable, ${ }^{\mathrm{b}} n(\%)$ & $15(8.9)$ & $2(3.4)$ \\
\hline ORR $(95 \% \mathrm{CI})(\%)$ & $3.0(1.0$ to 6.8$)$ & $5.2(1.1$ to 14.4$)$ \\
\hline $\operatorname{DCR}(\%)$ & 28.0 & 31.0 \\
\hline Median $(95 \% \mathrm{CI})$ duration of response in confirmed responders (weeks) & ne (28.7 to ne) & ne (ne to ne) \\
\hline Median (95\% CI) progression-free survival (weeks) & $5.9(5.9$ to 6.0$)$ & $5.9(5.7$ to 6.9$)$ \\
\hline Progression-free survival rate at 24 weeks $(95 \% \mathrm{CI})(\%)$ & 10.1 (5.9 to 15.5$)$ & $12.4(5.2$ to 22.8$)$ \\
\hline Median (95\% CI) overall survival (months) & 8.1 (6.4 to ne $)$ & 9.2 (4.3 to ne) \\
\hline Overall survival rate at 12 months $(95 \% \mathrm{CI})(\%)$ & 40.3 (29.6 to 50.7$)$ & 37.1 (18.3 to 56.2$)$ \\
\hline
\end{tabular}

Treatment responses are based on confirmed response according per Response Criterion In Solid Tumors version 1.1

$D C R$ disease control rate (defined as responses + stable disease), ne not estimable, ORR objective response rate

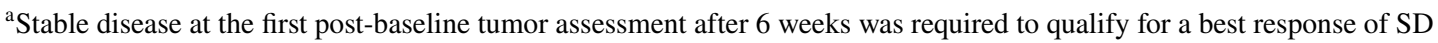

bIncludes "missing" and "not assessable"

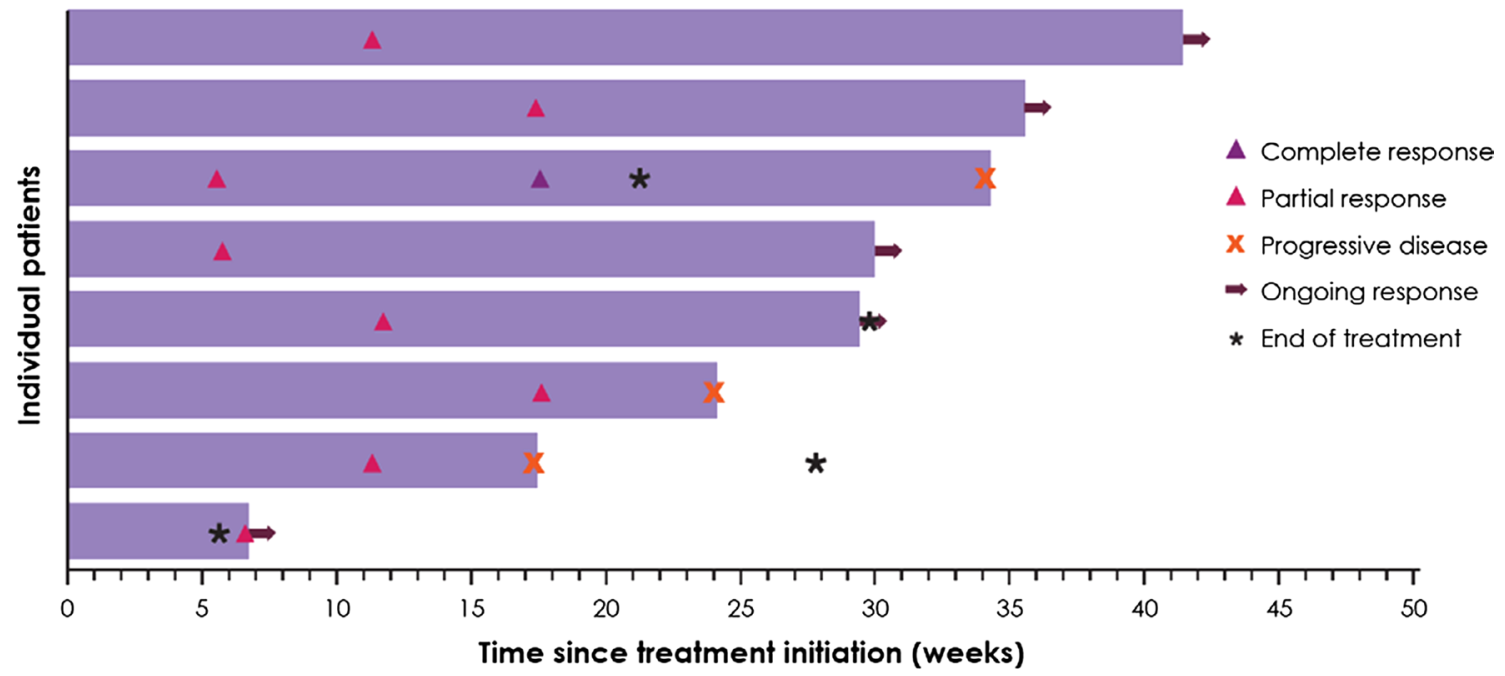

Fig. 1 Time to and duration of response for patients with confirmed or unconfirmed responses

ADCC, indicating the presence of a potential second mechanism of action [21-23]. However, no clinical data are available to show that ADCC contributes to the clinical activity of avelumab. Importantly, the frequency of immune cell subsets is not decreased following treatment with avelumab [29].

To date, the use of PD-L1 as a predictive biomarker for $\mathrm{MBC}$ remains controversial given the use of different PD-L1 antibodies and detection assays, various PD-L1 expression cutoffs, and non-standardized test designs [30, 31]. Studies of pembrolizumab (anti-PD-1) and atezolizumab (antiPD-L1) have included analyses of tumor PD-L1 expression in patients with TNBC $[17,19]$. In the phase 1b KEYNOTE-012 study of pembrolizumab in PD-L1+ TNBC
( $n=27$ evaluable patients), PD-L1 positivity was defined as expression in the stroma or in $\geq 1 \%$ of tumor cells based on IHC staining using the 22C3 PD-L1 antibody. In this PD-L1+ cohort, the ORR was $18.5 \%, 37.5 \%$ of evaluable patients had tumor shrinkage of any level, and the DCR was $25.9 \%$ [17]. An exploratory analysis suggested an association between PD-L1 score (percentage of inflammatory and tumor cells staining for PD-L1) and the probability of response and progression-free survival with pembrolizumab. Similarly, in a phase 1a study of atezolizumab in 115 patients with heavily pretreated TNBC, of whom 71 were PD-L1+ (based on $\geq 5 \%$ of tumor-infiltrating immune cells [IHC score of 2/3 using the SP142 assay]) and were 


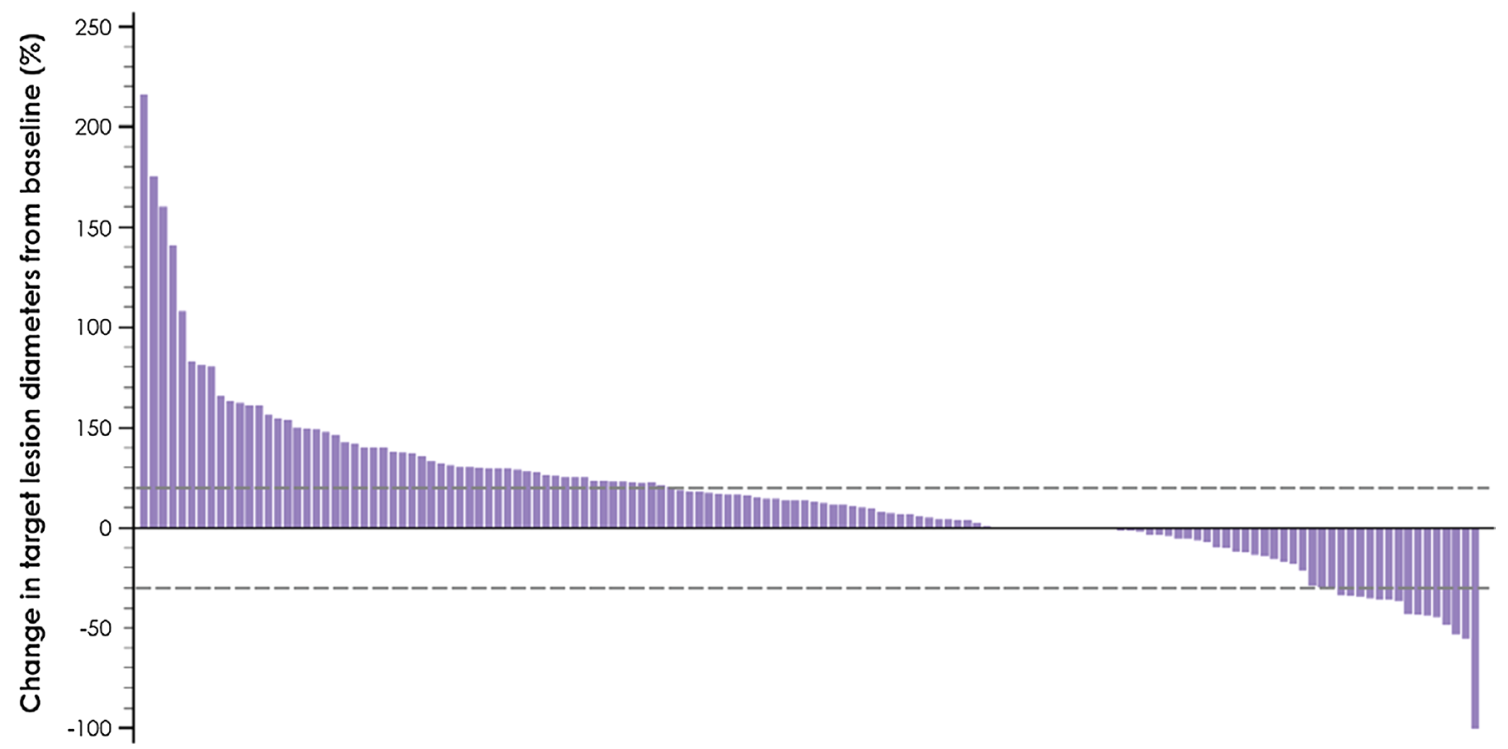

Fig. 2 Best change in target lesions from baseline in 140 evaluable patients with baseline tumor assessment and $\geq 1$ post-baseline assessment

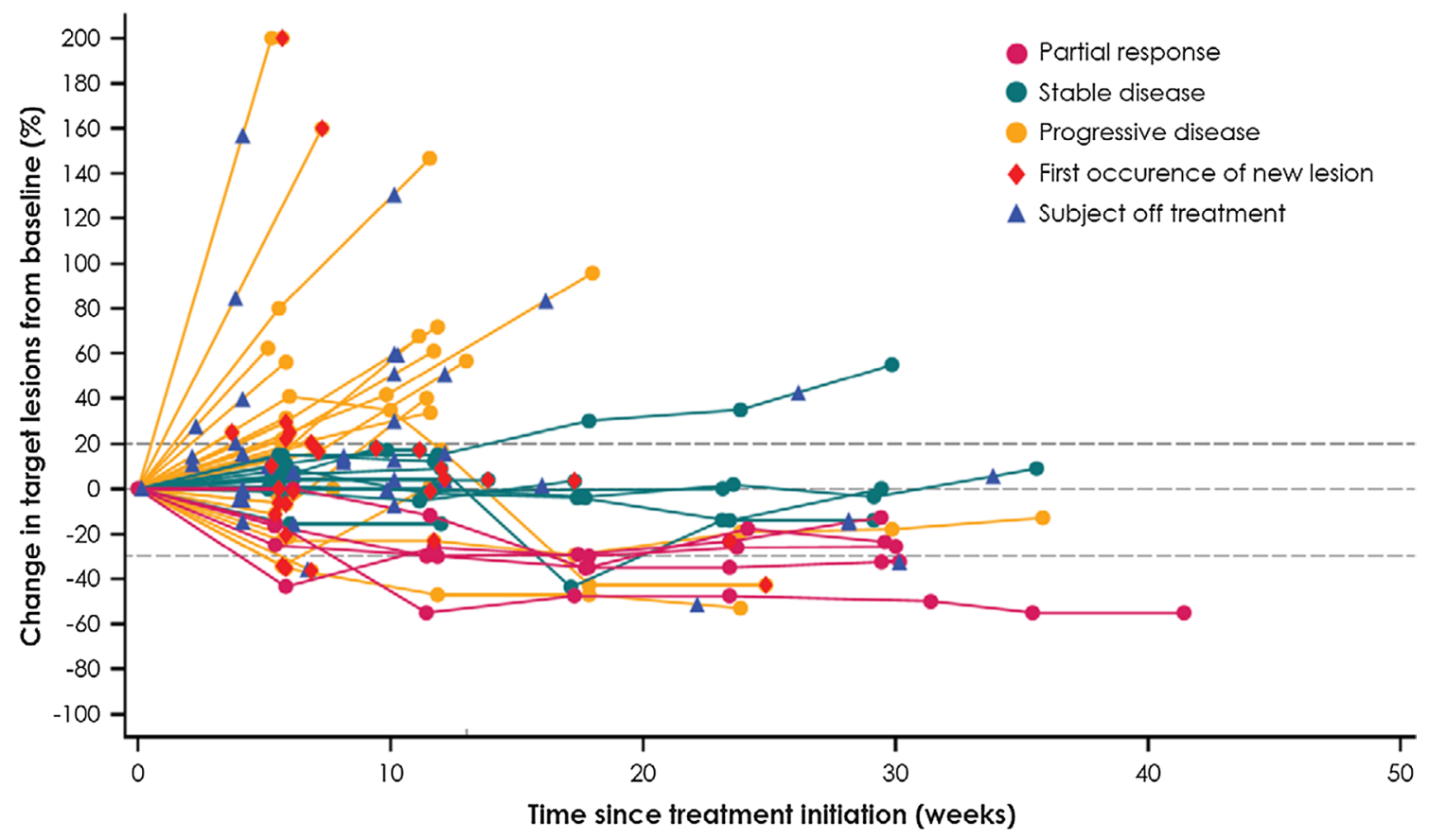

Fig. 3 Percent change in target lesions from baseline in 46 evaluable patients with TNBC with baseline tumor assessment and $\geq 1$ post-baseline assessment

considered evaluable for efficacy, the unconfirmed ORR was 13\% [19]. In our study, a possible trend toward a higher ORR was seen in patients with PD-L1+ versus PD-L1 - tumorassociated immune cells, both in the overall population $(16.7 \%$ vs. $1.6 \%)$ and in the TNBC subgroup $(22.2 \%$ vs. $2.6 \%$ ). The response rate to avelumab in patients with TNBC and PD-L1+ tumor-associated immune cells is comparable with the response rate of 18.5 and $13 \%$ reported for patients with PD-L1+ TNBC treated with pembrolizumab and atezolizumab, respectively [17, 19]. Although the small number of evaluable patients with PD-L1+ TILs in our study $(n=12)$ precludes any definitive conclusions, these data support the hypothesis that PD-L1 expression on TILs may predict response to checkpoint inhibitor therapy in breast cancer. In our study, unlike in the pembrolizumab and atezolizumab studies, PD-L1 expression was evaluated 
separately in tumor cells and tumor-associated immune cells as prespecified in the analysis plan, and the Dako PD-L1 IHC 73-10 pharmDx assay was used for the evaluation. Efforts to standardize testing for PD-L1 expression are underway, including the Blueprint PD-L1 IHC comparison project [32]. Data are not yet available to compare the performance of the 73-10 assay with that of other assays, although studies are ongoing, and the 73-10 assay will be included in phase 2 of the Blueprint study. Studies to characterize the potential of PD-L1 as a predictive biomarker for avelumab are ongoing.

In conclusion, our data show that the anti-PD-L1 antibody avelumab has a safety profile that is considered generally manageable and tolerable, and showed modest clinical activity in a heavily pretreated population of patients with MBC. Collectively, our findings and those of other studies suggest that durable clinical benefit can be achieved with anti-PD-1/PD-L1 monotherapy in a subset of patients with MBC, particularly TNBC [17-19]. Based on the results from single-agent immunotherapy in patients with MBC, studies of combination therapy that might increase the probability of treatment benefit are warranted, and promising clinical activity in TNBC has been reported for a treatment regimen of atezolizumab administered in combination with taxane chemotherapy (NCT01633970) and of pembrolizumab in combination with eribulin mesylate (NCT02513472) in preliminary studies $[33,34]$. An ongoing phase $1 \mathrm{~b} / 2$ study (JAVELIN Medley; NCT02554812), which includes a TNBC cohort, is currently assessing avelumab in combination with novel immunotherapies.

Acknowledgements We thank the patients and their families, investigators, coinvestigators, and the study teams at each of the participating centers and at Merck KGaA, Darmstadt, Germany and EMD Serono Research \& Development Institute, Inc., Billerica, MA, USA (a business of Merck KGaA, Darmstadt, Germany). This trial was sponsored by Merck KGaA, Darmstadt, Germany and is part of an alliance between Merck KGaA, Darmstadt, Germany and Pfizer, Inc., New York, NY, USA. Medical writing support was provided by ClinicalThinking, Inc., Hamilton, NJ, USA and funded by Merck KGaA, Darmstadt, Germany and Pfizer, New York, NY, USA.

Funding Merck KGaA, Darmstadt, Germany and Pfizer, Inc.

\section{Compliance with ethical standards}

Conflict of interest GJ Reports honoria from Novartis, Celgene, and Roche; consulting/advisory roles for Novartis and Celgene; research funding from Novartis, MSD, and Roche; travel, accommodations, expenses from Novartis, Roche, and GSK. AFT reports research funding (to institution) from Pfizer. RB reports honoraria from Amgen, Celgene, AstraZeneca, and Tesaro; consulting/advisory role, speaker's bureau fees, and travel, accommodations, and expenses for Heron Therapeutics. ML reports a leadership role and stock or other ownership for Seattle Genetics, Oncology analytics, and Geneyus. LE reports travel, accommodations, or expenses from Bayer Pharmaceuticals; consulting/advisory roles for Celgene, Vaccinex, Amgen, AstraZeneca, Syndax, Peregrine, eTHeRNA, Bayer, Molecuvax, and Gritstone; research funding from Genentech, Roche, EMD Serono, MaxCyte, MSD, As-
traZeneca, Aduro Biotech, and Corvus; and is an SGE to the FDA. BH reports consulting/advisory roles for Bayer, Gilead, and Biotheranostics and research funding from EMD Serono, MedImmune, and AstraZeneca. WE participated in speakers' bureau for Astellas and Medivation. JG reports research funding from EMD Serono. AvH and HJG are employees at Merck KGaA, Darmstadt, Germany. KC is an employee of EMD Serono, Inc., a subsidiary of Merck KGaA, Darmstadt, Germany. EH reports research funding (to institution) from Sarah Cannon Research Institute. All other authors have nothing to disclose.

Open Access This article is distributed under the terms of the Creative Commons Attribution 4.0 International License (http://creativecommons.org/licenses/by/4.0/), which permits unrestricted use, distribution, and reproduction in any medium, provided you give appropriate credit to the original author(s) and the source, provide a link to the Creative Commons license, and indicate if changes were made.

\section{Appendix}

See Tables 4, 5, 6, 7, 8, 9, and 10 .

Table 4 Additional patient demographics and disease characteristics

\begin{tabular}{lc}
\hline Characteristics, $n(\%)$ & $N=168$ \\
\hline Prior surgery & $161(95.8)$ \\
Prior radiotherapy & $139(82.7)$ \\
Prior anticancer therapies in any setting & \\
1 & $5(3.0)$ \\
2 & $27(16.1)$ \\
$\geq 3$ & $136(80.9)$ \\
Median (range) & $4.0(1-10)$ \\
Prior platinum regimen & \\
Carboplatin based & $36(21.4)$ \\
Cisplatin based & $9(5.4)$ \\
Type of prior anticancer therapy & \\
Chemotherapy & $168(100.0)$ \\
Hormonal therapy & $103(61.3)$ \\
Antibody therapy & $30(17.9)$ \\
Kinase inhibitor & $19(11.3)$ \\
Vaccines & $1(0.6)$ \\
Other & $36(21.4)$ \\
Intent of any prior therapy & \\
Neoadjuvant & $64(38.1)$ \\
Adjuvant & $111(66.1)$ \\
Metastatic & $137(81.5)$ \\
Locally advanced & $30(17.9)$ \\
Palliative & $7(4.2)$ \\
Best response to any prior anticancer therapy & \\
Complete response & $3(1.8)$ \\
Partial response & $9(5.4)$ \\
Stable disease & $33(9.6)$ \\
Progressive disease & $94(56.0)$ \\
Not assessable & $1(0.6)$ \\
Unknown & $13(7.7)$ \\
Not applicable & $15(8.9)$ \\
\hline
\end{tabular}


Table 5 Key eligibility criteria

\begin{tabular}{|c|c|}
\hline Inclusion criteria & Exclusion criteria \\
\hline Age $\geq 18$ years & Prior therapy with any drug targeting $\mathrm{T}$ cell coregulatory proteins \\
\hline $\begin{array}{l}\text { Histologically confirmed MBC that is refractory to or progressive after } \\
\text { standard-of-care therapy }\end{array}$ & $\begin{array}{l}\text { Concurrent anticancer therapy within } 4 \text { weeks of start of trial treatment, } \\
\text { use of hormonal agents within } 7 \text { days of start of trial treatment, or any } \\
\text { other concurrent investigational treatment }\end{array}$ \\
\hline $\begin{array}{l}\text { No more than three prior lines of cytotoxic therapy for metastatic } \\
\text { disease }\end{array}$ & Prior treatment with immunosuppressive agents such as steroids \\
\hline $\begin{array}{l}\text { Prior treatment with a taxane and an anthracycline, unless contraindi- } \\
\text { cated }\end{array}$ & Major surgery $\leq 4$ weeks prior to enrollment \\
\hline $\begin{array}{l}\text { Availability of a formalin-fixed, paraffin-embedded block containing } \\
\text { tumor tissue or unstained tumor slides suitable for PD-L1 expression } \\
\text { assessment }\end{array}$ & $\begin{array}{l}\text { Previous malignant disease other than } \mathrm{MBC} \text { within the last } 5 \text { years } \\
\text { except for basal or squamous cell carcinoma of the skin or cervical } \\
\text { carcinoma in situ }\end{array}$ \\
\hline ECOG performance status score of 0 or 1 & Metastases of the central nervous system \\
\hline $\begin{array}{l}\text { Measurable disease by RECIST version } 1.1 \text { or objective evidence of } \\
\text { disease without a measurable lesion }\end{array}$ & $\begin{array}{l}\text { Clinically significant illness, including infection, autoimmune disease } \\
\text { (other than diabetes mellitus type 1, vitiligo, psoriasis, hypothyroid } \\
\text { disease, or hyperthyroid disease not requiring immunosuppressive } \\
\text { treatment), cardiovascular disease, or a psychiatric condition affecting } \\
\text { the understanding or rendering of informed consent }\end{array}$ \\
\hline Estimated life expectancy of $\geq 3$ months & $\begin{array}{l}\text { Persisting toxicity of grade }>1 \text { related to prior therapy (except } \\
\text { grade } \leq 2 \text { sensory neuropathy) }\end{array}$ \\
\hline Adequate renal, hepatic, and hematologic function & $\begin{array}{l}\text { Known severe hypersensitivity to monoclonal antibodies, history of } \\
\text { anaphylaxis, or uncontrolled asthma }\end{array}$ \\
\hline Use of highly effective contraception & $\begin{array}{l}\text { Vaccination (other than inactivated vaccines) within } 55 \text { days of the first } \\
\text { dose of avelumab }\end{array}$ \\
\hline \multirow[t]{3}{*}{ Signed written informed consent } & Pregnancy or lactation \\
\hline & Known alcohol or drug abuse \\
\hline & Legal incapacity or limited legal capacity \\
\hline
\end{tabular}

ECOG Eastern Cooperative Oncology Group, $M B C$ metastatic breast cancer, PD-L1 programmed death-ligand 1, RECIST Response Evaluation Criteria In Solid Tumors

Table 6 Prior cytotoxic therapies

\begin{tabular}{lc}
\hline Therapy & Patients $(N=168)$ \\
\hline Cyclophosphamide & $132(78.6)$ \\
Paclitaxel & $108(64.3)$ \\
Doxorubicin & $94(56.0)$ \\
Docetaxel & $86(51.2)$ \\
Capecitabine & $79(47.0)$ \\
Fluorouracil & $38(22.6)$ \\
Carboplatin & $36(21.4)$ \\
Epirubicin & $34(20.2)$ \\
Trastuzumab & $30(17.9)$ \\
Bevacizumab & $29(17.3)$ \\
Everolimus & $26(15.5)$ \\
Nab-paclitaxel & $24(14.3)$ \\
Gemcitabine & $19(11.3)$ \\
Gemcitabine hydrochloride & $17(10.1)$ \\
Eribulin & $16(9.5)$ \\
Pegylated liposomal doxorubicin hydrochloride & $16(9.5)$ \\
Methotrexate & $12(7.1)$ \\
Vinorelbine tartrate & $10(6.0)$ \\
Cyclophosphamide with doxorubicin & $9(5.4)$ \\
Lapatinib & $7(4.2)$ \\
\hline
\end{tabular}


Table 6 (continued)

\begin{tabular}{|c|c|}
\hline Therapy & Patients $(N=168)$ \\
\hline Pertuzumab & $7(4.2)$ \\
\hline Cisplatin & $6(3.6)$ \\
\hline Trastuzumab emtansine & $6(3.6)$ \\
\hline Vinorelbine & $6(3.6)$ \\
\hline Eribulin mesylate & $3(1.8)$ \\
\hline Ixabepilone & $3(1.8)$ \\
\hline Cisplatin with docetaxel & $2(1.2)$ \\
\hline Cyclophosphamide with docetaxel/doxorubicin & $2(1.2)$ \\
\hline Cyclophosphamide with epirubicin hydrochloride/fluorouracil & $2(1.2)$ \\
\hline Cyclophosphamide with fluorouracil/methotrexate & $2(1.2)$ \\
\hline Doxorubicin hydrochloride & $2(1.2)$ \\
\hline Onartuzumab & $2(1.2)$ \\
\hline Veliparib & $2(1.2)$ \\
\hline PI3 kinase inhibitor & $2(1.2)$ \\
\hline Doxorubicin/cyclophosphamide and paclitaxel & $1(0.6)$ \\
\hline Carboplatin with gemcitabine & $1(0.6)$ \\
\hline Cetuximab & $1(0.6)$ \\
\hline 5-Fluorouracil, epirubicin, and cyclophosphamide & $1(0.6)$ \\
\hline Cyclophosphamide with epirubicin/fluorouracil & $1(0.6)$ \\
\hline Epirubicin hydrochloride & $1(0.6)$ \\
\hline Idarubicin & $1(0.6)$ \\
\hline Irinotecan & $1(0.6)$ \\
\hline Lapatinib ditosylate monohydrate & $1(0.6)$ \\
\hline Neratinib & $1(0.6)$ \\
\hline Olaparib & $1(0.6)$ \\
\hline Panitumumab & $1(0.6)$ \\
\hline Ruxolitinib & $1(0.6)$ \\
\hline Sorafenib & $1(0.6)$ \\
\hline
\end{tabular}

Table 7 Adverse events (related or unrelated) of any grade in $>5 \%$ of patients or of grade $\geq 3$ in any patient

\begin{tabular}{|c|c|c|c|c|c|c|}
\hline \multirow[t]{2}{*}{ Adverse event, $n(\%)$} & \multicolumn{6}{|c|}{ Patients $(N=168)$} \\
\hline & Any grade & Grade 1 & Grade 2 & Grade 3 & Grade 4 & Grade 5 \\
\hline Any event, $n(\%)$ & $161(95.8)$ & $24(14.3)$ & $57(33.9)$ & $48(28.6)$ & $10(6.0)$ & $22(13.1)$ \\
\hline Fatigue & $63(37.5)$ & $30(17.9)$ & $30(17.9)$ & $3(1.8)$ & 0 & 0 \\
\hline Nausea & $49(29.2)$ & $29(17.3)$ & $19(11.3)$ & $1(0.6)$ & 0 & 0 \\
\hline Constipation & $29(17.3)$ & $21(12.5)$ & $8(4.8)$ & 0 & 0 & 0 \\
\hline Decreased appetite & $29(17.3)$ & $19(11.3)$ & $10(6.0)$ & 0 & 0 & 0 \\
\hline Diarrhea & $29(17.3)$ & $22(13.1)$ & $7(4.2)$ & 0 & 0 & 0 \\
\hline Vomiting & $25(29.2)$ & $14(8.3)$ & $9(5.4)$ & $2(1.2)$ & 0 & 0 \\
\hline Back pain & $24(14.3)$ & $10(6.0)$ & $7(4.2)$ & $7(4.2)$ & 0 & 0 \\
\hline Cough & $24(14.3)$ & $19(11.3)$ & $5(3.0)$ & 0 & 0 & 0 \\
\hline Dyspnea & $24(14.3)$ & $10(6.0)$ & $4(2.4)$ & $9(5.4)$ & $1(0.6)$ & 0 \\
\hline Infusion-related reaction & $24(14.3)$ & $6(3.6)$ & $18(10.7)$ & 0 & 0 & 0 \\
\hline Arthralgia & $23(13.7)$ & $15(8.9)$ & $3(1.8)$ & $5(3.0)$ & 0 & 0 \\
\hline Dyspnea exertional & $23(13.7)$ & $15(8.9)$ & $6(3.6)$ & $1(0.6)$ & $1(0.6)$ & 0 \\
\hline Pyrexia & $21(12.5)$ & $18(10.7)$ & $2(1.2)$ & $1(0.6)$ & 0 & 0 \\
\hline Abdominal pain & $19(11.3)$ & $11(6.5)$ & $5(3.0)$ & $3(1.8)$ & 0 & 0 \\
\hline Abdominal pain upper & $19(11.3)$ & $7(4.2)$ & $11(6.5)$ & $1(0.6)$ & 0 & 0 \\
\hline Anemia & $17(10.1)$ & $2(1.2)$ & $5(3.0)$ & $9(5.4)$ & $1(0.6)$ & 0 \\
\hline Pleural effusion & $17(10.1)$ & $4(2.4)$ & $4(2.4)$ & $8(4.8)$ & $1(0.6)$ & 0 \\
\hline Urinary tract infection & $17(10.1)$ & $5(3.0)$ & $12(7.1)$ & 0 & 0 & 0 \\
\hline Asthenia & $16(9.5)$ & $7(4.2)$ & $6(3.6)$ & $3(1.8)$ & 0 & 0 \\
\hline
\end{tabular}


Table 7 (continued)

\begin{tabular}{|c|c|c|c|c|c|c|}
\hline \multirow[t]{2}{*}{ Adverse event, $n(\%)$} & \multicolumn{6}{|c|}{ Patients $(N=168)$} \\
\hline & Any grade & Grade 1 & Grade 2 & Grade 3 & Grade 4 & Grade 5 \\
\hline Edema peripheral & $15(8.9)$ & $8(4.8)$ & $6(3.6)$ & $1(0.6)$ & 0 & 0 \\
\hline Headache & $15(8.9)$ & $13(7.7)$ & $2(1.2)$ & 0 & 0 & 0 \\
\hline Elevated AST & $14(8.3)$ & $2(1.2)$ & $6(3.6)$ & $6(3.6)$ & 0 & 0 \\
\hline Influenza-like illness & $14(8.3)$ & $13(7.7)$ & $1(0.6)$ & 0 & 0 & 0 \\
\hline Pain in extremity & $13(7.7)$ & $5(3.0)$ & $5(3.0)$ & $3(1.8)$ & 0 & 0 \\
\hline Disease progression & $12(7.1)$ & 0 & 0 & $1(0.6)$ & $1(0.6)$ & $10(6.0)$ \\
\hline Musculoskeletal pain & $12(7.1)$ & $4(2.4)$ & $8(4.8)$ & 0 & 0 & 0 \\
\hline Noncardiac chest pain & $12(7.1)$ & $4(2.4)$ & $3(1.8)$ & $5(3.0)$ & 0 & 0 \\
\hline Abdominal distension & $11(6.5)$ & $6(3.6)$ & $4(2.4)$ & $1(0.6)$ & 0 & 0 \\
\hline Anxiety & $11(6.5)$ & $6(3.6)$ & $5(3.0)$ & 0 & 0 & 0 \\
\hline Decreased weight & $11(6.5)$ & $7(4.2)$ & $4(2.4)$ & 0 & 0 & 0 \\
\hline Dizziness & $11(6.5)$ & $7(4.2)$ & $3(1.8)$ & $1(0.6)$ & 0 & 0 \\
\hline Elevated ALT & $11(6.5)$ & $6(3.6)$ & $4(2.4)$ & $1(0.6)$ & 0 & 0 \\
\hline Hypertension & $11(6.5)$ & $4(2.4)$ & $5(3.0)$ & $2(1.2)$ & 0 & 0 \\
\hline Insomnia & $11(6.5)$ & $6(3.6)$ & $5(3.0)$ & 0 & 0 & 0 \\
\hline Musculoskeletal chest pain & $11(6.5)$ & $7(4.2)$ & $3(1.8)$ & $1(0.6)$ & 0 & 0 \\
\hline Hypothyroidism & $10(6.0)$ & $2(1.2)$ & $8(4.8)$ & 0 & 0 & 0 \\
\hline Muscle spasms & $10(6.0)$ & $10(6.0)$ & 0 & 0 & 0 & 0 \\
\hline Neck pain & $10(6.0)$ & $4(2.4)$ & $6(3.6)$ & 0 & 0 & 0 \\
\hline Dry skin & $9(5.4)$ & $8(4.8)$ & $1(0.6)$ & 0 & 0 & 0 \\
\hline Hypokalemia & $9(5.4)$ & $3(1.8)$ & $5(3.0)$ & 0 & $1(0.6)$ & 0 \\
\hline Pruritus & $9(5.4)$ & $7(4.2)$ & $2(1.2)$ & 0 & 0 & 0 \\
\hline Chest pain & $8(4.8)$ & $5(3.0)$ & $2(1.2)$ & $1(0.6)$ & 0 & 0 \\
\hline Elevated blood alkaline phosphatase & $7(4.2)$ & $2(1.2)$ & $3(1.8)$ & $2(1.2)$ & 0 & 0 \\
\hline Myalgia & $7(4.2)$ & $6(3.6)$ & 0 & $1(0.6)$ & 0 & 0 \\
\hline Elevated GGT & $6(3.6)$ & $1(0.6)$ & $1(0.6)$ & $2(1.2)$ & $2(1.2)$ & 0 \\
\hline Flank pain & $5(3.0)$ & $2(1.2)$ & $2(1.2)$ & $1(0.6)$ & 0 & 0 \\
\hline Hyponatremia & $5(3.0)$ & $2(1.2)$ & $1(0.6)$ & $2(1.2)$ & 0 & 0 \\
\hline Hypoxia & $5(3.0)$ & 0 & $3(1.8)$ & $2(1.2)$ & 0 & 0 \\
\hline Pneumonia & $5(3.0)$ & 0 & $1(0.6)$ & $4(2.4)$ & 0 & 0 \\
\hline Hypercalcemia & $4(2.4)$ & $2(1.2)$ & $1(0.6)$ & 0 & $1(0.6)$ & 0 \\
\hline Thrombocytopenia & $4(2.4)$ & $1(0.6)$ & 0 & 0 & $3(1.8)$ & 0 \\
\hline Respiratory failure & $4(2.4)$ & 0 & 0 & 0 & $2(1.2)$ & $2(1.2)$ \\
\hline Autoimmune hepatitis & $3(1.8)$ & 0 & 0 & $3(1.8)$ & 0 & 0 \\
\hline Axillary pain & $3(1.8)$ & $1(0.6)$ & $1(0.6)$ & $1(0.6)$ & 0 & 0 \\
\hline General physical health deterioration & $3(1.8)$ & 0 & 0 & $2(1.2)$ & 0 & $1(0.6)$ \\
\hline Hyperglycemia & $3(1.8)$ & 0 & $2(1.2)$ & $1(0.6)$ & 0 & 0 \\
\hline Lymphocyte count decreased & $3(1.8)$ & 0 & $2(1.2)$ & $1(0.6)$ & 0 & 0 \\
\hline Metastatic pain & $3(1.8)$ & $1(0.6)$ & 0 & $2(1.2)$ & 0 & 0 \\
\hline Pleuritic pain & $3(1.8)$ & $1(0.6)$ & $1(0.6)$ & $1(0.6)$ & 0 & 0 \\
\hline Pneumonitis & $3(1.8)$ & $1(0.6)$ & $1(0.6)$ & $1(0.6)$ & 0 & 0 \\
\hline Pneumothorax & $3(1.8)$ & $1(0.6)$ & $1(0.6)$ & $1(0.6)$ & 0 & 0 \\
\hline Proteinuria & $3(1.8)$ & $2(1.2)$ & 0 & $1(0.6)$ & 0 & 0 \\
\hline Sinus tachycardia & $3(1.8)$ & $1(0.6)$ & $1(0.6)$ & $1(0.6)$ & 0 & 0 \\
\hline Atrial fibrillation & $2(1.2)$ & 0 & 0 & $1(0.6)$ & $1(0.6)$ & 0 \\
\hline Cardiac tamponade & $2(1.2)$ & 0 & 0 & $1(0.6)$ & $1(0.6)$ & 0 \\
\hline Deep vein thrombosis & $2(1.2)$ & 0 & $1(0.6)$ & $1(0.6)$ & 0 & 0 \\
\hline Hematuria & $2(1.2)$ & $1(0.6)$ & 0 & $1(0.6)$ & 0 & 0 \\
\hline Hepatomegaly & $2(1.2)$ & $1(0.6)$ & 0 & $1(0.6)$ & 0 & 0 \\
\hline Hypophosphatemia & $2(1.2)$ & 0 & 0 & $2(1.2)$ & 0 & 0 \\
\hline International normalized ratio increased & $2(1.2)$ & $1(0.6)$ & 0 & $1(0.6)$ & 0 & 0 \\
\hline Jugular vein thrombosis & $2(1.2)$ & 0 & 0 & $2(1.2)$ & 0 & 0 \\
\hline
\end{tabular}


Table 7 (continued)

\begin{tabular}{|c|c|c|c|c|c|c|}
\hline \multirow[t]{2}{*}{ Adverse event, $n(\%)$} & \multicolumn{6}{|c|}{ Patients $(N=168)$} \\
\hline & Any grade & Grade 1 & Grade 2 & Grade 3 & Grade 4 & Grade 5 \\
\hline Metastases to meninges & $2(1.2)$ & 0 & $1(0.6)$ & 0 & $1(0.6)$ & 0 \\
\hline Neutrophil count decreased & $2(1.2)$ & $1(0.6)$ & 0 & $1(0.6)$ & 0 & 0 \\
\hline Platelet count decreased & $2(1.2)$ & 0 & $1(0.6)$ & $1(0.6)$ & 0 & 0 \\
\hline Radiation pneumonitis & $2(1.2)$ & $1(0.6)$ & 0 & $1(0.6)$ & 0 & 0 \\
\hline Rash papular & $2(1.2)$ & $1(0.6)$ & 0 & $1(0.6)$ & 0 & 0 \\
\hline Respiratory distress & $2(1.2)$ & 0 & 0 & $1(0.6)$ & 0 & $1(0.6)$ \\
\hline Acute hepatic failure & $1(0.6)$ & 0 & 0 & 0 & 0 & $1(0.6)$ \\
\hline Acute kidney injury & $1(0.6)$ & 0 & 0 & $1(0.6)$ & 0 & 0 \\
\hline Ataxia & $1(0.6)$ & 0 & 0 & $1(0.6)$ & 0 & 0 \\
\hline Bile duct obstruction & $1(0.6)$ & 0 & 0 & $1(0.6)$ & 0 & 0 \\
\hline Brain injury & $1(0.6)$ & 0 & 0 & 0 & 0 & $1(0.6)$ \\
\hline Bronchial obstruction & $1(0.6)$ & 0 & 0 & $1(0.6)$ & 0 & 0 \\
\hline Burning sensation & $1(0.6)$ & 0 & 0 & $1(0.6)$ & 0 & 0 \\
\hline Cardiac arrest & $1(0.6)$ & 0 & 0 & 0 & $1(0.6)$ & 0 \\
\hline Cardiac failure & $1(0.6)$ & 0 & 0 & 0 & $1(0.6)$ & 0 \\
\hline Cardio-respiratory arrest & $1(0.6)$ & 0 & 0 & 0 & 0 & $1(0.6)$ \\
\hline Cellulitis & $1(0.6)$ & 0 & 0 & $1(0.6)$ & 0 & 0 \\
\hline Cholestasis & $1(0.6)$ & 0 & 0 & $1(0.6)$ & 0 & 0 \\
\hline Coccydynia & $1(0.6)$ & 0 & 0 & $1(0.6)$ & 0 & 0 \\
\hline Dental caries & $1(0.6)$ & 0 & 0 & $1(0.6)$ & 0 & 0 \\
\hline Electrocardiogram QT prolonged & $1(0.6)$ & 0 & 0 & $1(0.6)$ & 0 & 0 \\
\hline Elevated blood potassium & $1(0.6)$ & 0 & 0 & $1(0.6)$ & 0 & 0 \\
\hline Elevated hepatic enzyme & $1(0.6)$ & 0 & 0 & $1(0.6)$ & 0 & 0 \\
\hline Failure to thrive & $1(0.6)$ & 0 & 0 & $1(0.6)$ & 0 & 0 \\
\hline Hemoptysis & $1(0.6)$ & 0 & 0 & $1(0.6)$ & 0 & 0 \\
\hline Hepatic encephalopathy & $1(0.6)$ & 0 & 0 & 0 & $1(0.6)$ & 0 \\
\hline Hepatic failure & $1(0.6)$ & 0 & 0 & 0 & 0 & $1(0.6)$ \\
\hline Hyperbilirubinemia & $1(0.6)$ & 0 & 0 & $1(0.6)$ & 0 & 0 \\
\hline Hypercalcemia of malignancy & $1(0.6)$ & 0 & 0 & 0 & $1(0.6)$ & 0 \\
\hline Hypertriglyceridemia & $1(0.6)$ & 0 & 0 & $1(0.6)$ & 0 & 0 \\
\hline Infection & $1(0.6)$ & 0 & 0 & $1(0.6)$ & 0 & 0 \\
\hline Liver disorder & $1(0.6)$ & 0 & 0 & $1(0.6)$ & 0 & 0 \\
\hline Malignant neoplasm progression & $1(0.6)$ & 0 & 0 & 0 & 0 & $1(0.6)$ \\
\hline Malignant pleural effusion & $1(0.6)$ & 0 & 0 & $1(0.6)$ & 0 & 0 \\
\hline Malnutrition & $1(0.6)$ & 0 & 0 & $1(0.6)$ & 0 & 0 \\
\hline Metastases to peripheral nervous system & $1(0.6)$ & 0 & 0 & 0 & $1(0.6)$ & 0 \\
\hline Monoparesis & $1(0.6)$ & 0 & 0 & $1(0.6)$ & 0 & 0 \\
\hline Myelodysplastic syndrome & $1(0.6)$ & 0 & 0 & 0 & $1(0.6)$ & 0 \\
\hline Neutropenia & $1(0.6)$ & 0 & 0 & 0 & $1(0.6)$ & 0 \\
\hline Obstructive uropathy & $1(0.6)$ & 0 & 0 & $1(0.6)$ & 0 & 0 \\
\hline Pain in hip, back, and right lower leg & $1(0.6)$ & 0 & 0 & $1(0.6)$ & 0 & 0 \\
\hline Paraparesis & $1(0.6)$ & 0 & 0 & 0 & $1(0.6)$ & 0 \\
\hline Pathological fracture & $1(0.6)$ & 0 & 0 & $1(0.6)$ & 0 & 0 \\
\hline Pleural fistula & $1(0.6)$ & 0 & 0 & $1(0.6)$ & 0 & 0 \\
\hline Pulmonary arterial hypertension & $1(0.6)$ & 0 & 0 & $1(0.6)$ & 0 & 0 \\
\hline Pulmonary embolism & $1(0.6)$ & 0 & 0 & 0 & 0 & $1(0.6)$ \\
\hline Pulmonary hypertension & $1(0.6)$ & 0 & 0 & 0 & 0 & $1(0.6)$ \\
\hline Sepsis & $1(0.6)$ & 0 & 0 & 0 & 0 & $1(0.6)$ \\
\hline Spinal cord compression & $1(0.6)$ & 0 & 0 & $1(0.6)$ & 0 & 0 \\
\hline Tumor invasion & $1(0.6)$ & 0 & 0 & 0 & 0 & $1(0.6)$ \\
\hline Tumor pain & $1(0.6)$ & 0 & 0 & $1(0.6)$ & 0 & 0 \\
\hline
\end{tabular}

$A L T$ alanine aminotransferase, $A S T$ aspartate aminotransferase, $G G T \gamma$-glutamyl transferase 
Table 8 Potential immunerelated, treatment-related adverse events by grade
Table 9 Confirmed ORR by subgroup

\begin{tabular}{|c|c|c|c|c|c|c|}
\hline \multirow[t]{2}{*}{ Adverse event, $n(\%)$} & \multicolumn{6}{|c|}{ Patients $(N=168)$} \\
\hline & Any grade & Grade 1 & Grade 2 & Grade 3 & Grade 4 & Grade 5 \\
\hline Any event, $n(\%)$ & $17(10.1)$ & $4(2.4)$ & $9(5.4)$ & $3(1.8)$ & $1(0.6)$ & $\mathbf{0}$ \\
\hline Hypothyroidism & $8(4.8)$ & $1(0.6)$ & $7(4.2)$ & 0 & 0 & 0 \\
\hline Autoimmune hepatitis ${ }^{\mathrm{a}}$ & $3(1.8)$ & 0 & 0 & $3(1.8)$ & 0 & 0 \\
\hline Pneumonitis & $3(1.8)$ & $1(0.6)$ & $1(0.6)$ & $1(0.6)$ & 0 & 0 \\
\hline Thrombocytopenia & $2(1.2)$ & $1(0.6)$ & 0 & 0 & $1(0.6)$ & 0 \\
\hline ANA positive & $1(0.6)$ & $1(0.6)$ & 0 & 0 & 0 & 0 \\
\hline Dry eye & $1(0.6)$ & $1(0.6)$ & 0 & 0 & 0 & 0 \\
\hline Elevated rheumatoid factor & $1(0.6)$ & $1(0.6)$ & 0 & 0 & 0 & 0 \\
\hline Hyperthyroidism & $1(0.6)$ & $1(0.6)$ & 0 & 0 & 0 & 0 \\
\hline Pemphigoid $^{\mathrm{b}}$ & $1(0.6)$ & 0 & $1(0.6)$ & 0 & 0 & 0 \\
\hline
\end{tabular}

The numbers in bold are the total number of immune related evens according to grade ANA antinuclear antibody

a Autoimmune hepatitis temporarily resolved with steroid treatment, but led to discontinuation in two patients; the third patient who experienced autoimmune hepatitis died of acute liver failure in a setting of progressive liver metastasis

${ }^{\mathrm{b}}$ Pemphigoid resolved following drug interruption but ultimately led to treatment discontinuation

\begin{tabular}{lll}
\hline Subgroup & $n / N 1$ & ORR \% (95\% CI) \\
\hline Age (years) & & \\
$<65$ & $4 / 140$ & $2.9(0.8,7.2)$ \\
$\geq 65$ & $1 / 28$ & $3.6(0.1,18.3)$ \\
Race & & \\
White & $3 / 143$ & $2.1(0.4,6.0)$ \\
Black & $2 / 25$ & $8.0(1.0,26.0)$ \\
ECOG & & \\
0 & $3 / 83$ & $3.6(0.8,10.2)$ \\
$\geq 1$ & $2 / 85$ & $2.4(0.3,8.2)$ \\
Prior lines for metastatic disease ${ }^{\mathrm{a}}$ & & \\
$\leq 1$ & $2 / 45$ & $4.4(0.5,15.1)$ \\
2 & $2 / 35$ & $5.7(0.7,19.2)$ \\
$\geq 3$ & $1 / 88$ & $1.1(0,6.2)$ \\
Biomarker group & & \\
TNBC & $3 / 58$ & $5.2(1.1,14.4)$ \\
HER2- (ER+ or PR+) & $2 / 72$ & $2.8(0.3,9.7)$ \\
HER2+ & $0 / 26$ & $0(0,13.2)$ \\
Unknown & $0 / 12$ & $0(0,26.5)$ \\
\hline
\end{tabular}

ECOG PS Eastern Cooperative Oncology Group performance status, ER estrogen receptor, HER2 human epidermal growth factor receptor 2, N1 number of evaluable patients, $O R R$ objective response rate, $P R$ progesterone receptor, $T N B C$ triple-negative breast cancer, $N 1$ number of evaluable patients

${ }^{a}$ Regimen for locally advanced/metastatic disease may have included hormonal therapy, either alone or in combination with chemotherapy. Systemic therapies that were not necessarily cytotoxic are included in the number of prior regimens reported here, but the number of cytotoxic therapies permitted was $\leq 3$

${ }^{\mathrm{b}}$ Unknown molecular subtype was due to incomplete information in the medical records database (ER/ PR status known, but HER2 status unknown in four patients) or to information collected retrospectively (molecular subtype status was from post-baseline samples in eight patients and, therefore, was not used for baseline characterization 
Table 10 Confirmed response, progression-free survival, and overall survival in patient subgroups defined by PD-L1 expression in tumor or immune cells

\begin{tabular}{|c|c|c|c|c|}
\hline & PD-L1+ & PD-L1- & $P$ value $^{\mathrm{a}}$ & Hazard ratio $(95 \% \mathrm{CI})$ \\
\hline \multicolumn{5}{|l|}{$\geq 1 \%$ Tumor cells, any intensity } \\
\hline Prevalence, $n$ & 85 & 51 & - & - \\
\hline ORR (95\% CI), n/N1 (\%) & $2 / 85(2.4[0.3,8.2])$ & $2 / 51(3.9[0.5,13.5])$ & 0.631 & - \\
\hline Median PFS (95\% CI) (weeks) & $5.9(5.7,6.0)$ & $6.0(5.9,6.0)$ & - & $1.183(0.815,1.716)$ \\
\hline PFS rate at 24 weeks $(95 \% \mathrm{CI})(\%)$ & $6.2(2.1,13.6)$ & $12.8(5.3,23.8)$ & - & \\
\hline Median OS (95\% CI) (months) & $6.5(3.7,9.2)$ & $8.3(6.3$, ne $)$ & - & $1.331(0.815,2.174)$ \\
\hline OS rate at 12 months $(95 \% \mathrm{CI})(\%)$ & $35.6(24.2,47.1)$ & $36.8(14.8,59.3)$ & - & \\
\hline \multicolumn{5}{|l|}{$\geq 5 \%$ Tumor cells, any intensity } \\
\hline Prevalence, $n$ & 23 & 113 & - & - \\
\hline ORR (95\% CI), $n / N 1(\%)$ & $1 / 23(4.3[0.1,21.9])$ & $3 / 113(2.7[0.6,7.6])$ & 0.528 & - \\
\hline Median PFS (95\% CI) (weeks) & $6.0(5.7,7.1)$ & $5.9(5.9,6.0)$ & - & $0.782(0.473,1.290)$ \\
\hline PFS rate at 24 weeks $(95 \%$ CI $)(\%)$ & $15.5(3.3,36.0)$ & $7.7(3.6,13.8)$ & - & \\
\hline Median OS (95\% CI) (months) & $6.5(2.2$, ne $)$ & $7.5(5.1,11.3)$ & - & $1.057(0.556,2.010)$ \\
\hline OS rate at 12 months $(95 \% \mathrm{CI})(\%)$ & ne & $35.9(23.7,48.2)$ & - & \\
\hline \multicolumn{5}{|l|}{$\geq 25 \%$ Tumor cells, high intensity $(\geq 2+)$} \\
\hline Prevalence, $n$ & 3 & 133 & - & - \\
\hline ORR (95\% CI), n/N1 (\%) & $0 / 3(0[0,70.8])$ & $4 / 133(3.0[0.8,7.5])$ & 1.000 & - \\
\hline Median PFS (95\% CI) (weeks) & $6.0(5.4$, ne $)$ & $5.9(5.9,6.0)$ & - & $0.695(0.172,2.813)$ \\
\hline PFS rate at 24 weeks $(95 \% \mathrm{CI})(\%)$ & ne & $8.6(4.5,14.5)$ & - & \\
\hline Median OS (95\% CI) (months) & $9.2($ ne, ne) & $6.8(4.9,10.8)$ & - & $0.441(0.061,3.177)$ \\
\hline OS rate at 12 months $(95 \% \mathrm{CI})(\%)$ & $0($ ne, ne $)$ & $36.3(25.0,47.6)$ & - & \\
\hline \multicolumn{5}{|c|}{$\geq 10 \%$ Tumor-associated immune cells, any intensity } \\
\hline Prevalence, $n$ & 12 & 124 & - & - \\
\hline ORR (95\% CI), $n / N 1(\%)$ & $2 / 12(16.7[2.1,48.4])$ & $2 / 124(1.6[0.2,5.7])$ & 0.039 & - \\
\hline Median PFS (95\% CI) (weeks) & $6.1(2.3,24,1)$ & $5.9(5.9,6.0)$ & - & $0.656(0.341,1.263)$ \\
\hline PFS rate at 24 weeks $(95 \% \mathrm{CI})(\%)$ & $25.0(6.0,50.5)$ & $7.0(3.2,12.9)$ & - & \\
\hline Median OS (95\% CI) (months) & $11.3(1.4$, ne $)$ & $6.8(4.7,9.2)$ & - & $0.620(0.250,1.541)$ \\
\hline OS rate at 12 months $(95 \% \mathrm{CI})(\%)$ & $33.3(1.7,74.4)$ & $37.4(27.4,47.4)$ & - & \\
\hline
\end{tabular}

ne not estimable, $N 1$ number of patients with evaluable PD-L1 expression, $O R R$ objective response rate, $O S$ overall survival, $P D-L 1$ programmed death-ligand 1, PFS progression-free survival

${ }^{\mathrm{a}}$ Fisher's exact test

\section{References}

1. O'Shaughnessy J (2005) Extending survival with chemotherapy in metastatic breast cancer. Oncologist 10(Suppl 3):20-29

2. National Cancer Institute (2016) SEER cancer stat facts: female breast cancer. National Cancer Institute, Bethesda, p 2016

3. National Comprehensive Cancer Network (V2 2017) (2017) NCCN clinical practice guidelines in oncology: breast cancer. National Comprehensive Cancer Network, Orlando

4. Dent R, Trudeau M, Pritchard KI et al (2007) Triple-negative breast cancer: clinical features and patterns of recurrence. Clin Cancer Res 13:4429-4434

5. Anders CK, Abramson V, Tan T et al (2016) The evolution of triple-negative breast cancer: from biology to novel therapeutics. Am Soc Clin Oncol Educ Book 35:34-42

6. Andre F, Zielinski CC (2012) Optimal strategies for the treatment of metastatic triple-negative breast cancer with currently approved agents. Ann Oncol 23:46-51

7. Postow MA, Callahan MK, Wolchok JD (2015) Immune checkpoint blockade in cancer therapy. J Clin Oncol 33:1974-1982
8. Mittendorf EA, Philips AV, Meric-Bernstam F et al (2014) PD-L1 expression in triple-negative breast cancer. Cancer Immunol Res 2:361-370

9. Schalper KA, Velcheti V, Carvajal D et al (2014) In situ tumor PD-L1 mRNA expression is associated with increased TILs and better outcome in breast carcinomas. Clin Cancer Res 20:2773-2782

10. Wimberly H, Brown JR, Schalper K et al (2015) PD-L1 expression correlates with tumor-infiltrating lymphocytes and response to neoadjuvant chemotherapy in breast cancer. Cancer Immunol Res 3:326-332

11. Dong H, Strome SE, Salomao DR et al (2002) Tumor-associated B7-H1 promotes T-cell apoptosis: a potential mechanism of immune evasion. Nat Med 8:793-800

12. Freeman GJ, Long AJ, Iwai Y et al (2000) Engagement of the PD-1 immunoinhibitory receptor by a novel B7 family member leads to negative regulation of lymphocyte activation. J Exp Med 192:1027-1034

13. Iwai Y, Ishida M, Tanaka Y et al (2002) Involvement of PD-L1 on tumor cells in the escape from host immune system and 
tumor immunotherapy by PD-L1 blockade. Proc Natl Acad Sci USA 99:12293-12297

14. Stanton SE, Disis ML (2016) Clinical significance of tumorinfiltrating lymphocytes in breast cancer. J Immunother Cancer 4:59

15. Cimino-Mathews A, Thompson E, Taube JM et al (2016) PD-L1 (B7-H1) expression and the immune tumor microenvironment in primary and metastatic breast carcinomas. Hum Pathol 47:52-63

16. Topalian SL, Drake CG, Pardoll DM (2015) Immune checkpoint blockade: a common denominator approach to cancer therapy. Cancer Cell 27:450-461

17. Nanda R, Chow LQ, Dees EC et al (2016) Pembrolizumab in patients with advanced triple-negative breast cancer: phase Ib KEYNOTE-012 study. J Clin Oncol 34:2460-2467

18. Emens L, Braiteh F, Cassier P et al (2015) Inhibition of PD-L1 by MPDL3280A leads to clinical activity in patients with metastatic triple-negative breast cancer (TNBC). Cancer Res 75:2859

19. Schmid P, Cruz C, Braiteh FS et al (2017) Atezolizumab in metastatic TNBC (mTNBC): long-term clinical outcomes and biomarker analysis. Cancer Res 77:2986

20. Heery CR, O'Sullivan-Coyne G, Madan RA et al (2017) Avelumab for metastatic or locally advanced previously treated solid tumours (JAVELIN Solid Tumor): a phase 1a, multicohort, doseescalation trial. Lancet Oncol 18:587-597

21. Boyerinas B, Jochems C, Fantini M et al (2015) Antibody-dependent cellular cytotoxicity activity of a novel anti-PD-L1 antibody avelumab (MSB0010718C) on human tumor cells. Cancer Immunol Res 3:1148-1157

22. Fujii R, Friedman ER, Richards J et al (2016) Enhanced killing of chordoma cells by antibody-dependent cell-mediated cytotoxicity employing the novel anti-PD-L1 antibody avelumab. Oncotarget 7:33498-33511

23. Grenga I, Donahue RN, Lepone LM et al (2016) A fully human IgG1 anti-PD-L1 MAb in an in vitro assay enhances antigenspecific T-cell responses. Clin Transl Immunol 5:e83

24. Kaufman HL, Russell J, Hamid O et al (2016) Avelumab in patients with chemotherapy-refractory metastatic Merkel cell carcinoma: a multicentre, single-group, open-label, phase 2 trial. Lancet Oncol 17:1374-1385
25. Gulley JL, Rajan A, Spigel DR et al (2017) Avelumab for patients with previously treated metastatic or recurrent non-small-cell lung cancer (JAVELIN Solid Tumor): dose-expansion cohort of a multicentre, open-label, phase $1 \mathrm{~b}$ trial. Lancet Oncol 18:599-610

26. Apolo AB, Infante JR, Balmanoukian A et al (2017) Avelumab, an anti-programmed death-ligand 1 antibody, in patients with refractory metastatic urothelial carcinoma: results from a multicenter, phase Ib study. J Clin Oncol 35:2117-2124

27. Bavencio (avelumab) injection [package insert] (2017) Darmstadt. Merck KGaA, Darmstadt

28. Eisenhauer EA, Therasse P, Bogaerts J et al (2009) New response evaluation criteria in solid tumours: revised RECIST guideline (version 1.1). Eur J Cancer 45:228-247

29. Donahue RN, Lepone LM, Grenga I et al (2017) Analyses of the peripheral immunome following multiple administrations of avelumab, a human IgG1 anti-PD-L1 monoclonal antibody. J Immunother Cancer 5:13

30. Patel SP, Kurzrock R (2015) PD-L1 expression as a predictive biomarker in cancer immunotherapy. Mol Cancer Ther 14:847-856

31. Wang X, Teng F, Kong L et al (2016) PD-L1 expression in human cancers and its association with clinical outcomes. Onco Targets Ther 9:5023-5039

32. Hirsch FR, McElhinny A, Stanforth D et al (2016) PD-L1 Immunohistochemistry assays for lung cancer: results from phase 1 of the "blueprint PD-L1 IHC assay comparison project". J Thorac Oncol 12:208-222

33. Adams S, Diamond J, Hamiton E et al (2016) Phase Ib trial of atezolizumab in combination with nab-paclitaxel in patients with metastatic triple-negative breast cancer (mTNBC). J Clin Oncol 34:1009

34. Tolaney S, Savulsky C, Aktan G et al (2017) Phase 1 b/2 study to evaluate eribulin mesylate in combination with pembrolizumab in patients with metastatic triple-negative breast cancer. Eur J Cancer 72:S16 